\title{
Erythema multiforme in leprosy
}

\author{
Alice Machado Miranda ${ }^{1 /+}$, Sérgio Luiz Gomes Antunes ${ }^{1}$, José Augusto Costa Nery ${ }^{1}$, \\ Anna Maria Sales', Mario José dos Santos Pereira², Euzenir Nunes Sarno'
}

\author{
${ }^{1}$ Laboratório de Hanseníase, Instituto Oswaldo Cruz-Fiocruz, Rio de Janeiro, RJ, Brasil \\ ${ }^{2}$ Departamento de Fisiologia, Universidade do Estado Rio de Janeiro, Rio de Janeiro, RJ, Brasil
}

The clinical course of leprosy is often interrupted by reactions, which are acute inflammatory episodes that can be classified as type I or type II. Type II reactions can present as cutaneous lesions that resemble erythema multiforme (EM). EM is classically associated with drug allergies or pre-existing viral infections. However, the differential diagnostic criteria of the diverse causative agents remain controversial. The aim of this study was to determine both the clinical relevance and the morphological and immunohistochemical characteristics of the EM-like lesions during the course of type II leprosy reactions. Twenty-seven skin biopsies were taken from typical EM-like lesions of multibacillary patients and reviewed; their histological features were correlated to their clinical aspects. Then, a computer-assisted morphometric analysis was performed to measure the extent of angiogenesis during these acute episodes. The histopathological and immunohistochemical analysis of the EM lesions revealed that they shared the same features that have been previously described for ENL, including immunopositivity in the identical cell-mediated immune markers. Our results point to leprosy as the cause of the EM-like lesions in our patients. Therefore, leprosy should be considered in the differential diagnosis of EM.

Key words: leprosy - erythema multiforme - erythema nodosum leprosum

Leprosy is a chronic infectious disease that is caused by the obligate intracellular parasite Mycobacterium leprae. Leprosy remains a major worldwide health care concern in numerous underdeveloped countries. In Brazil and India, two emerging global economies, new cases continue to be diagnosed despite the advent of successful chemotherapeutic treatments. In Brazil, approximately 34,000 new cases were reported in 2011, resulting in a penetrance rate of approximately 1.2 cases per 10,000 inhabitants (MS/SVS 2011). The clinical course of chronic leprosy is often interrupted by reactions, which are acute inflammatory responses that can occur before, during or after chemotherapy. The estimated risk of a LP experiencing at least one reaction episode during medical follow-up can be as high as $60 \%$ in multibacillary (MB) patients who are undergoing multidrug therapy (MDT) (Nery et al. 1998). These reactions have been broadly classified as type I or reversal reactions (RRs), which most commonly affect borderline patients [borderline tuberculoid, borderline-borderline and borderline lepromatous $(\mathrm{BL})]$, or type II or erythema nodosum leprosum (ENL), which affects the lepromatous patients [BL and lepromatous forms (LL)]. The RRs are characterised by the reactivation of old lesions and the appearance of new lesions that present as swollen, erythematous plaques and that are frequently accompanied by nerve damage. In ENL cases, painful erythematous

Financial support: CNPq, PO\&M/IOC-FIOCRUZ

+ Corresponding author: almiran@ioc.fiocruz.br

Received 27 March 2012

Accepted 11 August 2012 dermal nodules appear and are often associated with inflammatory systemic symptoms, including fever, malaise, anorexia, iritis, orchitis, lymphadenopathy and usually neuritis (Bryceson \& Pfalzgraff 1990).

Although necrotic lesions have sometimes been observed in type II reactions (Esquenazi et al. 2008), few cases of erythema multiform (EM) were reported as a leprosy reaction (Rea \& Modlin 1993, Ganapati \& Pai 2004). The risk factors and mechanisms that determine the onset of these reactions have been topics of great interest because of their connection to the physical deformities that result from nerve damage (Illarramendi et al. 2001).

Recent evidence indicates transient increases in $M$. leprae-specific cell-mediated immunity (CMI) during RRs, but the role of this immunity in ENL must be clarified. Immune complex deposits have been implicated in the cutaneous lesions of ENL (Wemambu et al. 1966) but require verification. Furthermore, high levels of pro-inflammatory cytokines have been consistently demonstrated in type I and type II reactions, both within the lesions and in the sera during such episodes (Laal et al. 1985, Modlin et al. 1985, Sarno et al. 1991, Moraes et al. 1999).

EM has been observed in connection with many other conditions, including herpes virus infections, chlamydia and with the use of drugs such as amoxicillin (Brice et al. 1989, Gonzalez-Delgado et al. 2006). This pathology remains idiopathic in at least $35 \%$ of affected patients. Various skin lesions, such as macules, papules, vesicles and bullae, are present, but the so-called "iris" or target lesion is a primary characteristic of EM (Fritsch \& Maldonado 1999).

Angiogenesis, a developmental and physiological process, occurs in interferon (IFN) $\gamma$ and/or tumour necrosis factor (TNF)-induced inflammatory reactions, tissue repair, rheumatoid arthritis and tumours (Sato et al. 1990, Folkman \& Shing 1992). The factors that control 
vascular formation include bacterial lipopolysaccharide (LPS), vascular endothelial growth factor and fibroblast growth factor (FGF) (Folkman \& Klagsbrun 1987). The role of angiogenesis in leprosy and its associated reactions remains unclear (Antunes et al. 2000, Bhandarkar et al. 2007). The regular histopathological examination of ENL samples has revealed the apparent involvement of the vasculature (oedema and angiogenesis) in the surrounding inflammatory infiltrate of the deep dermis, which is consistent with the vascular alterations that Antunes et al. (2000) and Bhandarkar et al. (2007) observed in the lepromatous pole of the disease. This study aimed to quantitatively characterise the angiogenic process in type II leprosy reactions.

We attempted to establish both the histopathological characteristics and clinical relevance of EM-like lesions during the course of progressive leprosy in 27 patients who presented with EM-like lesions during their clinical follow-ups. The immunoreactivity of the reactional cutaneous lesions for immunological markers provides information about the immune response in this type of reaction and identifies the possible differences between this atypical type II reaction and classical ENL.

If the EM-like clinical presentation is an uncommon variant of the manifestation of the type II leprosy reaction, then its early diagnosis will be crucial for applying prompt anti-reaction therapy, thus preventing the disabilities caused by the peripheral neuropathy that often complicates these episodes.

\section{SUBJECTS, MATERIALS AND METHODS}

Patients and tissue specimens - From 1996-2006, 27 leprosy patients (LPs) (22 men and 5 women, aged 21-67 years) who visited the leprosy outpatient unit of the Oswaldo Cruz Foundation (Fiocruz), Rio de Janeiro, Brazil and who presented with EM-like lesions were enrolled in the study. The patients were classified according to the Ridley and Jopling (1966) criteria. Eight of the patients $(30 \%)$ presented with EM-like lesions without a previous diagnosis of leprosy and 19 patients were MB patients, who were actively undergoing treatment $(10 \mathrm{LL}$ and 9 $\mathrm{BL})$. The bacterial index (BI) ranged from +3 to +5 . After the patients provided written, informed consent, a 6 $\mathrm{mm}$-punch biopsy was obtained from a plaque or an iris lesion for diagnostic purposes in accordance with the Fiocruz Ethical Committee guidelines.

The skin samples were divided into two parts; one part was fixed in a $10 \%$ neutral buffered-formalin and paraffin-embedded and the other was snap-frozen in liquid nitrogen, embedded in OCT compound and stored in liquid nitrogen at $-170^{\circ} \mathrm{C}$ until further use (Tissue Tek, Miles Lab, USA).

Previously studied immunohistological markers in a group of ENL samples that were collected from other LPs were compared with the EM-like sample results. The results of the immunohistochemical procedures are shown in Table I.

Specific chemotherapy (MDT-WHO) for MB leprosy was neither interrupted nor introduced during the study.

TABLE I

Immunohistological markers

\begin{tabular}{|c|c|c|c|c|c|c|c|c|c|c|c|}
\hline \multirow[b]{2}{*}{$\begin{array}{l}\text { Patient } \\
\text { number }\end{array}$} & \multirow[b]{2}{*}{$\begin{array}{l}\text { Type of } \\
\text { reaction }\end{array}$} & \multicolumn{4}{|c|}{ Epidermis } & \multicolumn{6}{|c|}{ Dermis } \\
\hline & & HLA-DR & CD1 & ICAM-1 & CD3 & CD1 & CD3 & CD4 & CD8 & $\begin{array}{l}\text { CD4/ } \\
\text { CD8 }\end{array}$ & TNF \\
\hline 22 & EM & +++ & 3.5 & + & 0.4 & 18 & 42.2 & 41.5 & 26.5 & 1.5 & +++ \\
\hline 5 & EM & +++ & 11.0 & + & 0.5 & 8 & 36.5 & ND & 30.2 & ND & +++ \\
\hline 4 & EM & +++ & 4.4 & ++ & 2.5 & 12 & 39.3 & 31.0 & 28.0 & 1.1 & ++ \\
\hline 6 & EM & +++ & 3.6 & ++ & 2.2 & 4 & 37.5 & 41.5 & 18.6 & 2.2 & ND \\
\hline 25 & EM & +++ & 13.2 & ++ & 4.6 & 6 & 48.0 & 39.5 & 33.2 & 1.2 & ++ \\
\hline 26 & EM & ++ & 3.0 & + & 1.4 & 3 & 37.5 & 38.5 & 15.0 & 2.5 & + \\
\hline 8 & EM & ++ & 3.0 & + & 0 & 6 & 42.7 & 32.0 & 25.5 & 1.2 & ++ \\
\hline 27 & EM & ++ & 2.1 & + & 0 & 0 & 45.0 & 41.0 & 39.2 & 1.0 & +++ \\
\hline 24 & EM & + & 9.7 & ++ & 2.6 & 4 & 40.5 & 41.7 & 26.0 & 1.6 & + \\
\hline 21 & EM & + & 2.3 & + & 0.6 & 3 & 53.6 & 45.0 & 32.7 & 1.4 & +++ \\
\hline 1 & ENL & +++ & 6.0 & ++ & 3.3 & 9 & 51.8 & ND & 35.6 & ND & + \\
\hline 2 & ENL & +++ & 6.4 & + & 0 & 15 & 45.2 & 39.2 & 33.0 & 1.2 & +++ \\
\hline 3 & ENL & +++ & 5.3 & + & 0.2 & 6 & 36.5 & 24.0 & ND & ND & ++ \\
\hline 4 & ENL & ++ & ND & 0 & 0,3 & 5 & 46.3 & 33.8 & ND & ND & ND \\
\hline 5 & ENL & ++ & 13.2 & ++ & 14.6 & 3 & 56.2 & 48.2 & 26.2 & 1.8 & ++ \\
\hline 6 & ENL & + & 5.1 & + & 0 & 18 & 40.8 & 25.5 & 20.6 & 1.2 & + \\
\hline 7 & ENL & + & 3.0 & + & 1.5 & 7 & 43.5 & 48.6 & 27.6 & 1.7 & ++ \\
\hline 8 & ENL & 0 & 5.6 & + & 1.7 & 0 & 47.5 & 34.5 & 26.0 & 1.3 & +++ \\
\hline 9 & ENL & 0 & 8.5 & 0 & 0 & 10 & 33.0 & 32.0 & 28.0 & 1.1 & + \\
\hline 10 & ENL & 0 & 2.8 & + & 1.5 & 4 & 42.5 & 38.6 & 24.5 & 1.5 & ++ \\
\hline
\end{tabular}

EM: erythema multiforme; ENL: erythema nodosum leprosum; HLA: human leukocyte antigen; ICAM: intercellular adhesion molecule; TNF: tumour necrosis factor; ND: not determined. 
The MDT consisted of supervised monthly doses of rifampicin $(600 \mathrm{mg})$ and clofazimine $(300 \mathrm{mg})$ together with self-administered, daily doses of dapsone $(100 \mathrm{mg})$ and doses of clofazimine $(100 \mathrm{mg})$ every other day over a consecutive 12 or 24 -month period. Thalidomide ( 400 $\mathrm{mg}$ /day) was used to treat the EM-like events. Prednisone $(1 \mathrm{mg} / \mathrm{kg} /$ day $)$ was administered to seven patients given that their clinical symptoms persisted after one week of thalidomide treatment. Two female patients were satisfactorily treated with $1.200 \mathrm{mg} /$ day of pentoxifylline. The participants received no further medication and none terminated treatment.

Histopathology - The formalin-fixed specimens were serially cut into $5 \mu \mathrm{m}$-thick sections and stained with haematoxylin-eosin, Wade's stain for acid-fast bacilli, Gomori's trichrome stain and Weigert's stain for elastic fibres. Table II shows the evaluated morphological parameters. In all cases, two patients experienced EM-like lesions, as diagnosed by dermatologists. The clinical diagnoses were confirmed by histopathology.

Immunohistochemistry - Frozen samples were serially cut in a cryostat, applied to silane-coated glass slides and stained using an avidin-biotin-peroxidase method, as previously described (Sampaio et al. 1993). Briefly, the sections were fixed in cold acetone and sequentially incubated with methanol- $\mathrm{H}_{2} \mathrm{O}_{2}$ to block the endogenous peroxidases, followed by incubation with a $10 \%$ normal horse serum (Vector Laboratories, USA) and then with the monoclonal antibodies listed below for $60 \mathrm{~min}$. In sequence, the sections were first incubated with biotin-conjugated horse anti-mouse $\operatorname{IgG}$ for $30 \mathrm{~min}$ and then with the avidin-biotin-peroxidase complex (Vectastain ABC kit, Vector Laboratories, USA) for another $30 \mathrm{~min}$. Between the incubation periods, the slides were thoroughly washed with phosphate buffered saline (PBS), $\mathrm{pH}$ 7.4. The reactions were developed using amino-ethyl-carbazole (AEC, Sigma, USA), counterstained with Mayer's haematoxylin and analysed with an optical microscope using a semi-quantitative method. As a control, the primary or secondary antibody was omitted. Moreover, to investigate the evolution of the immunological activation markers, the skin biopsies were sequentially studied in the following three distinct situations: (i) at the time of diagnosis, (ii) during the reaction (EM) and (iii) after the reaction lesions subsided ( 2 months after each episode).

Antibodies - The following primary monoclonal antibodies selected for this study were diluted in PBS $\mathrm{pH}$

TABLE II

Histopathological data

\begin{tabular}{|c|c|c|c|c|c|}
\hline Patients & Bulla & $\begin{array}{l}\text { Occupation rate } \\
(\%)\end{array}$ & Oedema & $\begin{array}{l}\text { Inflammatory cells } \\
\text { in the infiltrate }\end{array}$ & AFB \\
\hline 1 & No & 50 & +++ & PMN, L, M, P & +++ \\
\hline 2 & No & 90 & +++ & PMN, L, M & +++ \\
\hline 3 & No & 80 & ++ & PMN, L, M & +++ \\
\hline 4 & No & 30 & ++ & PMN, L, M, P & +++ \\
\hline 5 & No & 30 & 0 & PMN, L, FM, P & +++ \\
\hline 6 & No & 40 & ++ & PMN, L, M, P & +++ \\
\hline 7 & No & 10 & + & PMN, L, M & + \\
\hline 8 & No & 40 & +++ & PMN, L, FM & ++ \\
\hline 9 & No & 30 & + & PMN, M, L, FM, P & ++ \\
\hline 10 & Yes & 80 & ++ & PMN, L, M, P & +++ \\
\hline 11 & No & 20 & ++ & PMN, M, L, FM & + \\
\hline 12 & Yes & 80 & +++ & PMN, L, FM & ++ \\
\hline 13 & No & 70 & + & PMN, L, FM, P & + \\
\hline 14 & Yes & 40 & +++ & PMN, M, L, FM & +++ \\
\hline 15 & No & 50 & ++ & PMN, L, M & +++ \\
\hline 16 & No & 30 & ++ & PMN, M, FM, P & +++ \\
\hline 17 & Yes & 70 & +++ & PMN, M, FM, P & + \\
\hline 18 & No & 30 & ++ & PMN, L, M, FM & ++ \\
\hline 19 & No & 40 & ++ & $\mathrm{L}, \mathrm{M}, \mathrm{PMN}$ & +++ \\
\hline 20 & No & 20 & ++ & PMN, L, M, FM, P & +++ \\
\hline 21 & No & 70 & +++ & PMN, L, M, FM & ++ \\
\hline 22 & No & 50 & + & M, L, FM & ++ \\
\hline 23 & No & 50 & ++ & PMN, L, M, FM, P & + \\
\hline 24 & No & 60 & ++ & PMN, M, FM, P & + \\
\hline 25 & No & 40 & ++ & $\mathrm{PMN}, \mathrm{M}, \mathrm{P}$ & ++ \\
\hline 26 & Yes & 80 & ++ & PMN, L, M, FM, P & +++ \\
\hline 27 & No & 30 & +++ & PMN, L, M, FM, P & +++ \\
\hline
\end{tabular}

AFB: acid fast bacilli; FM: foamy macrophage; L: lymphocyte; M: macrophage; P: plasma cell; PMN: polymorphonuclear. 
7.4 at the final concentration ratios indicated within the following parentheses: anti-CD1, anti-HLA-Dr and CD68 (1:50), anti-CD3, CD4 and CD8 (1:25) from BectonDickinson (USA), anti-TNF (1:20) from R\&D Systems (USA) and anti-intercellular adhesion molecule (ICAM)-1 (1:25) from Immunotech (France).

The quantification of immunoreactive cells - The quantification of the immunoreactive cells was performed according to the following protocols using an $40 \mathrm{X}$ objective lens and a pair of 10X ocular lenses: (i) the per cent of immunoreactive cells found in 200 cells was determined for CD3, CD4, CD8 and TNF, (ii) the per cent of immunoreactive cells for HLA-DR in the epidermis was assigned as "+" when only the Langerhans cells were labelled, "++" when $30-70 \%$ of the epidermal cells were immunopositive and "+++" when more than $70 \%$ of the cells were immunoreactive, (iii) the total number of immunoreactive cells in the epidermis was counted for CD1 in the epidermis and the average number of immunoreactive cells per field of examined in the upper dermis was counted for CD1 in the dermis and (iv) for ICAM-1, the immunostaining values were assigned as "+" when the epidermal basal cells were stained and "++" when the immunolabelled cells were detected throughout the other epidermal layers.

Computer-assisted morphometric analysis - Formalin-fixed specimens were cut for this study and stained with anti-factor VIII (1:20) from the DAKO Corporation, without counterstaining. Two-three microscopic fields (10X objective) were captured from each section that included both the superficial and the reticular dermis. The stained vessels were counted and measured using a semi-automated quantitation function of the ImagePro plus 4.0 software. The data were saved in an ASCII file and analysed using the statistical software MicroCal Origin 5.01 (MicroCal Software Inc USA). The analysed parameters included the total number of vessels and the area that they occupied. The Wilcoxon paired test was used to evaluate the significance of the differences between the means of the measured vessels before and during the reactions. The Mann-Whitney non-parametric test for two independent groups of samples was applied to compare the quantification of the immunoreactive cells of the EM-like and the ENL groups; p-values $<5 \%$ were considered statistically significant. Statistical analysis was performed with the R Program.

\section{RESULTS}

The 27 patients in this study were selected over a 10year period at a reference centre for leprosy. Although its actual incidence is impossible to determine, the EMlike episode frequency rate in the 600 type II reaction episodes that were diagnosed at this centre during the period of study was $4.5 \%$ (27 patients). Eight patients in our study $(30 \%)$ presented with EM-like lesions as the first manifestation of leprosy, which was diagnosed by a positive BI and by the presence of fragmented acid-fast bacilli (AFB) in the biopsies. Eleven patients (40\%) were still undergoing MDT treatment and 30\% $(\mathrm{n}=8)$ developed EM after being discharged. Eighty-one per cent of the patients undergoing treatment, as well as post-treatment patients, had suffered previous ENL reactions, but only nine patients presented with concomitant ENL during the EM-like episodes studied.

Eighteen patients $(66.6 \%)$ presented with typical vesico-bullous target lesions, whereas the other diagnosed patients presented with various skin erythematous patches, plaques, papules and ulcers (Fig. 1A, C).

Twenty-one patients $(77.7 \%)$ reported or exhibited other reaction episodes in their evolving clinical history. Five patients $(18.5 \%)$ reported no reaction episode up to the clinical presentation of the EM-like lesions (Table III).

The skin samples taken from the EM-like lesions invariably exhibited a slight to moderately thickened epidermis with up to 12 layers of keratinocytes, among which spongiosis and exocytosis were mild but regularly occurring (Fig. 1B, D). Unexpectedly, a small number of unevenly distributed apoptotic cells were observed in these cases.

Histological examination revealed the presence of subepidermal bullae in four cases. In all of the other cases, a mild-to-prominent oedema was observed in the superficial dermis in association with a cellular infiltration of predominantly lymphocytes and neutrophils (Fig. 1B, D). This cellular infiltration was sparse and limited to the perivascular region within the hypodermis. Foamy macrophages carrying fragmented bacilli were apparent in all of the cases, ranging from numerous in untreated patients to sparse in patients who were released from treatment. The nerve bundles invariably exhibited a number of histological changes, particularly the thickening of the perineurium, infiltration by inflammatory cells and the presence of AFB.

The histological features were particularly well correlated to the clinical aspects of the lesion selected for the biopsy. The oedema in the superficial dermis was prevalent in the "iris" or clinically bullous lesion samples and the inflammatory infiltrates occupied more than $70 \%$ of the biopsy area. Conversely, the oedema was mild and the percentage of the dermis that was occupied by the cellular infiltrate was moderate (occupying between $30-70 \%$ of the entire section area) when elevated papules or plaque lesions samples were examined. The infiltrates were sparse, surrounding microvessels and occupied less than $30 \%$ of the section area, in patch lesion samples (Fig. 1).

Vascular changes were apparent in all cases, with the most common altered features as follows: (i) angiogenesis $(85.1 \%)$, (ii) dilation (81.4\%) and congestion (66.6\%) of the lymphatic vessels, (iii) inflammatory cells (predominantly lymphocytes) encroaching on the wall $(88.8 \%)$, (iv) disruption of the elastic layer within the arterioles $(50 \%)$, (v) the presence of polymorphonuclear leukocytes surrounding, but not within the wall (96.2\%), and (vi) the occlusion of the lumen by fibrin or hypertrophic endothelial cells (51.8\%) and AFB within the wall (37\%). Fibrinoid degeneration and thrombosis were not detected in our examinations (Fig. 2A, B).

HLA-DR, ICAM-1, CD1a ${ }^{+}$cells, CD3, CD4/CD8 ratio and $\mathrm{CD} 68$ levels were analysed in $10 \mathrm{EM}$ biopsies (Fig. 1E-H). Five EM-like biopsies demonstrated 
intense HLA-DR labelling $(+++)$, three were moderate $(++)$ and two were slight $(+)$ in the epidermis. ICAM-1 immunoreactivity of the keratinocytes was confined to a few foci within the basal layers of the six samples $(+)$, whereas immunoreactivity was observed within the suprabasal layers of the epidermis in four samples. In six patients, these sites coincided with the presence of grouped $\mathrm{CD}^{+} \mathrm{T}$-cells within the epidermis (Fig. 1H). The mean $\mathrm{CD} 4 / \mathrm{CD} 8$ ratio was not significantly different between the ENL and the EM groups $(p<0.45)$.
Although the mean Langerhans cell (LC) count varied considerably among all of the cases studied from 2.113.2 (Fig. 1E), no significant difference was detected between the ENL and the EM groups $(p<0.9)$. Within the dermis, the LCs were predominantly localised proximal to the blood vessels within the upper dermis and their total number varied depending on the density of the epidermal LCs. A significant influx of inflammatory cells was observed in the EM and the ENL lesions, which consisted of neutrophils and $\mathrm{CD}^{+} \mathrm{T}$-cells. In addition,

TABLE III

Clinical data of erythema multiforme (EM) patients

\begin{tabular}{|c|c|c|c|c|c|c|c|c|c|c|}
\hline Patient & $\begin{array}{l}\text { Age } \\
\text { (years) }\end{array}$ & Sex & $\begin{array}{l}\text { Onset } \\
\text { time }\end{array}$ & BI & RJ & $\begin{array}{l}\text { Reactional } \\
\text { lesion }\end{array}$ & $\begin{array}{l}\text { Concomitant } \\
\text { ENL }\end{array}$ & Symptoms & $\begin{array}{l}\text { Treatment of } \\
\text { reaction }\end{array}$ & $\begin{array}{l}\text { Other } \\
\text { reactions }\end{array}$ \\
\hline 1 & 21 & $\mathrm{~F}$ & BT & 3 & - & MA, UL, PL & No & NI & Pred & ENL, EM \\
\hline 2 & 40 & M & BT & 4 & - & PL, ND & Yes & $\begin{array}{l}\text { Fever, adenomegaly, } \\
\text { nasal obstruction }\end{array}$ & Thalid + Pred & NI \\
\hline 3 & 23 & M & $\mathrm{BT}$ & 5 & - & PL, TL & No & $\begin{array}{l}\text { Fever, adenomegaly, } \\
\text { eye alterations, malaise }\end{array}$ & Thalid + Pred & ENL \\
\hline 4 & 26 & M & BT & 4 & - & PL, TL & No & Fever adenomegaly, malaise & Thalid & ENL, EM \\
\hline 5 & 56 & M & BT & 4 & - & PL, TL & No & NI & Thalid & ENL, EM \\
\hline 6 & 43 & $\mathrm{~F}$ & BT & 4 & - & PL, UL, TL & No & NI & Pento & ENL, EM \\
\hline 7 & 21 & M & BT & 4 & - & PL, TL & No & $\begin{array}{l}\text { Fever, anorexia, } \\
\text { myalgia, cephalalgia }\end{array}$ & Thalid + Pred & ENL, EM \\
\hline 8 & 66 & M & BT & 5 & - & PA, UL, ND, PL & Yes & $\begin{array}{l}\text { Fever, myalgia, anorexia, } \\
\text { asthenia, adenomegaly }\end{array}$ & Thalid & ENL \\
\hline 9 & 22 & $\mathrm{~F}$ & 4th MDT & 3 & $\mathrm{BL}$ & $\mathrm{PL}, \mathrm{ND}, \mathrm{TL}$ & Yes & Fever, arthralgia & Pred & ENL \\
\hline 10 & 39 & M & 8th MDT & 3 & $\mathrm{BL}$ & PL, TL, UL & No & Fever, myalgia, anorexia & Thalid + Pred & ENL \\
\hline 11 & 62 & M & 9th MDT & 3 & BL & PL & No & $\begin{array}{l}\text { Fever, adenomegaly, } \\
\text { nasal obstruction }\end{array}$ & Thalid & EM \\
\hline 12 & 41 & M & 10th MDT & 4 & LL & ND, TL & Yes & NI & Thalid & ENL \\
\hline 13 & 25 & M & 11th MDT & 5 & LL & PL, UL, ND, TL & Yes & NI & Thalid & NI \\
\hline 14 & 46 & M & 15th MDT & 4 & LL & PL, TL, BU & No & Fever & Thalid + Pred & ENL, EM \\
\hline 15 & 41 & M & 15th MDT & 3 & BL & ND, TL & Yes & Asthenia, adenomegaly & Thalid + Pred & ENL \\
\hline 16 & 39 & $\mathrm{~F}$ & 17th MDT & 3 & LL & ND & Yes & Fever, myalgia & Pred & ENL, NEU \\
\hline 17 & 47 & M & 20th MDT & 4 & LL & PL, TL & No & NI & Thalid & ENL \\
\hline 18 & 67 & M & 22th MDT & 4 & $\mathrm{BL}$ & PL, UL, ND & No & Fever, arthalgia & Thalid & - \\
\hline 19 & 29 & M & 22th MDT & 5 & LL & PL, TL & No & Fever, adenomegaly & Pentox & ENL, EM \\
\hline 20 & 33 & M & $\mathrm{PT}$ & 3 & BL & PA, PL, ND & Yes & Arthralgia & Thalid & EM \\
\hline 21 & 36 & M & $\mathrm{PT}$ & 3 & $\mathrm{BL}$ & MA, PL, TL & No & NI & Thalid & NI \\
\hline 22 & 27 & $\mathrm{~F}$ & PT & 3 & LL & PA, PL, TL & No & $\begin{array}{l}\text { Fever, asthenia, } \\
\text { myalgia, malaise }\end{array}$ & Pred + Thalid & EM \\
\hline 23 & 45 & M & PT & 3 & $\mathrm{BL}$ & PL & No & $\begin{array}{c}\text { Arthralgia, } \\
\text { edema (lower limbs) }\end{array}$ & Thalid & ENL \\
\hline 24 & 50 & M & $\mathrm{PT}$ & 4 & BL & PL, ND, TL & yes & Fever, adenomegaly & Thalid & ENL, EM \\
\hline 25 & 36 & M & $\mathrm{PT}$ & 4 & LL & PL, TL & no & NI & NT & ENL \\
\hline 26 & 58 & M & PT & 6 & LL & PA, UL, TL, PL & no & NI & Pred & NI \\
\hline 27 & 29 & M & PT & 4 & LL & PL, TL & no & NI & NI & ENL \\
\hline
\end{tabular}

BI: bacterial index; BL: borderline lepromatous; BT: before treatment; BU: bulla; ENL: erythema nodosum leprosum; F: female; LL: lepromatous leprosy; M: male; MA: macule; MDT: multidrug therapy; ND: nodular lesions; NEU: reactional neuritis; NI: not informed; NT: not treated; PA: patch; Pento: pentoxifiline; PL: plaque; Pred: prednisone; PT: post-tratmente; RJ: RidleyJopling classification; Thalid: thalidomide; TL: target lesion; UL: ulcer. 
$\mathrm{CD} 4^{+} \mathrm{T}$-cells predominated over $\mathrm{CD} 8^{+}$cells in all of the cases, many infiltrating cells were likely macrophages, as they were immunolabelled by anti-TNF monoclonal antibodies. Moreover, in all of the cases, the infiltrating cells were likely macrophages, as they were immunolabelled by anti-TNF monoclonal antibodies. Although
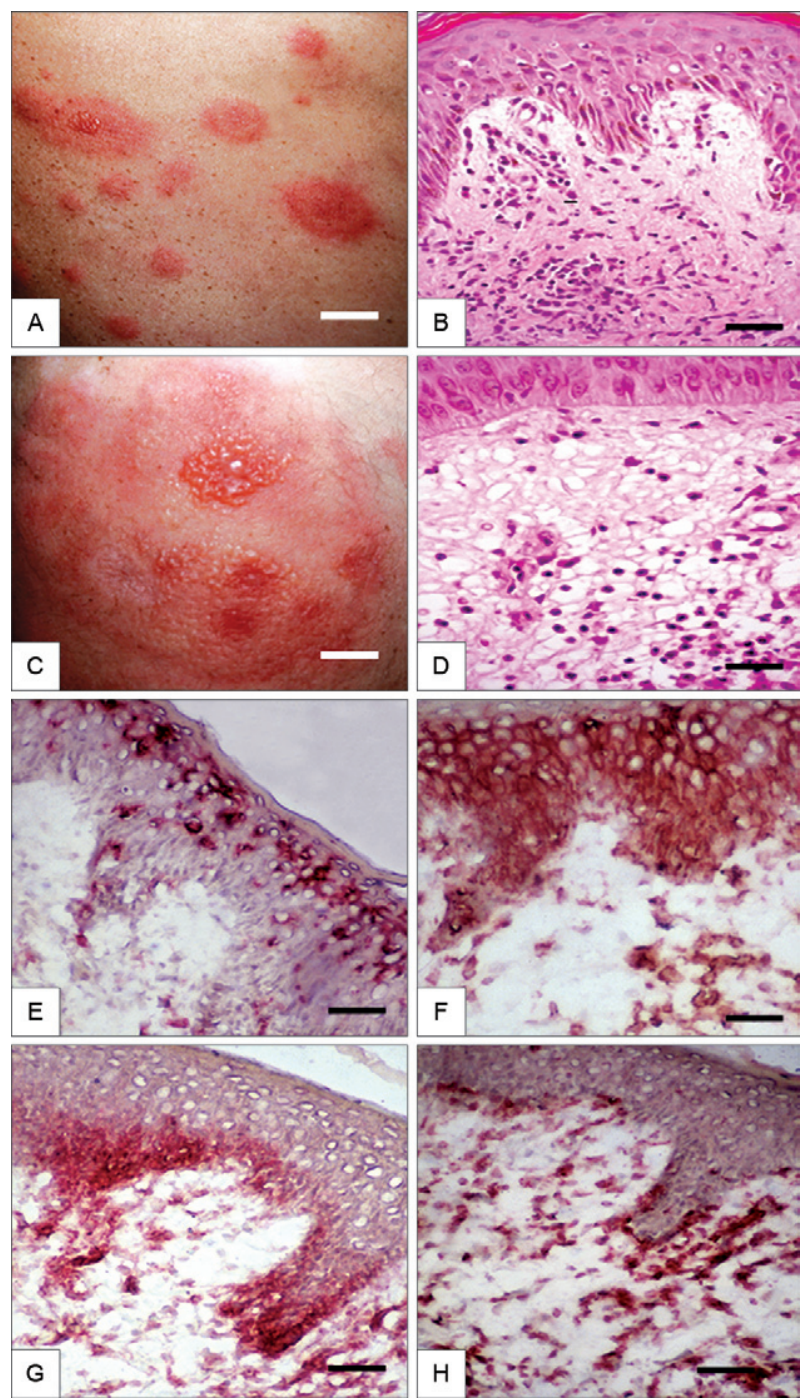

Fig. 1: clinical lesions of erythema multiforme (EM) correlate with histopathological aspects of skin biopsies and show cell-mediated immunity (CMI) tissue parameters. A: papules and target lesions on dorsal region $(\mathrm{Bar}=1.5 \mathrm{~cm})$; B: skin biopsy of target lesion showing intraepithelial oedema associated with exocytosis. Marked oedema in papillary dermis $(\mathrm{H} \& \mathrm{E}, \mathrm{Bar}=50 \mu \mathrm{m})$; $\mathrm{C}$ : bulla-like lesions on the chest $(\mathrm{Bar}=1.5 \mathrm{~cm})$; $\mathrm{D}$ : corresponding biopsy showing severe oede$\mathrm{ma}$ and polymorphonuclear infiltrate in superficial dermis (H\&E, Bar $=40 \mu \mathrm{m}$ ); E-H: immunohistological markers in EM cutaneous biopsy specimens; E: high number of $\mathrm{CD1}^{+}$immune labelled cells is present in biopsies of EM lesions ( $\mathrm{Bar}=50 \mu \mathrm{m})$; F: positive human leukocyte antigen (HLA)-DR expression in the epidermis and in dermal infiltrates (Bar: $35 \mu \mathrm{m}$ ); G: positive intercellular adhesion molecule (ICAM)-1 expression in basal keratinocytes and blood vessels of an EM patient $(\mathrm{Bar}=50 \mu \mathrm{m}) ; \mathrm{H}$ : intraepithelial CD3-immunoreactive cells coincided with the ICAM-1 immune labelling (Bar: $50 \mu \mathrm{m}$ ). this staining was faint and diffuse (+) in two of the EM cases, the immunoreactivity was strong in other four cases. The comparison of the quantity of immunoreactive cells in the EM-like and ENL groups is summarised as follows: $\mathrm{CD}^{+}$cells in the epidermis of the EM-like lesions $=5.5 \pm 4.0-\mathrm{ENL}=6.2 \pm 3.1(\mathrm{p}<0.3), \mathrm{CD1}^{+}$cells in the dermis of the EM-like lesions $=6.4 \pm 5.2-\mathrm{ENL}=$ $7.7 \pm 5.4(\mathrm{p}<0.4), \mathrm{CD} 4 / \mathrm{CD} 8$ ratio of the EM-like lesions $=1.5 \pm 0.5-\mathrm{ENL}=1.4 \pm 0.2(\mathrm{p}<0.9), \mathrm{TNF}^{+}$cells of the EM-like lesions $=2.2 \pm 0.8-\mathrm{ENL}=1.8 \pm 0.7(\mathrm{p}<0.4)$, HLA-DR ${ }^{+}$cells of the EM-like lesions $=2.3 \pm 0.8-\mathrm{ENL}$ $=1.5 \pm 1.2(\mathrm{p}<0.16)$ and ICAM- $1^{+}$cells of the EM-like lesions $=1.4 \pm 0.5-\mathrm{ENL}=1.0 \pm 0.6(\mathrm{p}<0.6)$.

A comparison of sequential skin samples taken from one EM patient before, during and two months after the reaction subsided revealed that the reaction lesion differed from the pre and post-reaction biopsies in the extent of HLA-DR expression, the number of LCs within the epidermis and the dermal CD4/CD8 ratios. All of these values increased in the reaction biopsies and decreased afterwards (data not shown).

The quantitative evaluation of the blood vessels by morphometric analysis was performed in six biopsy spec-
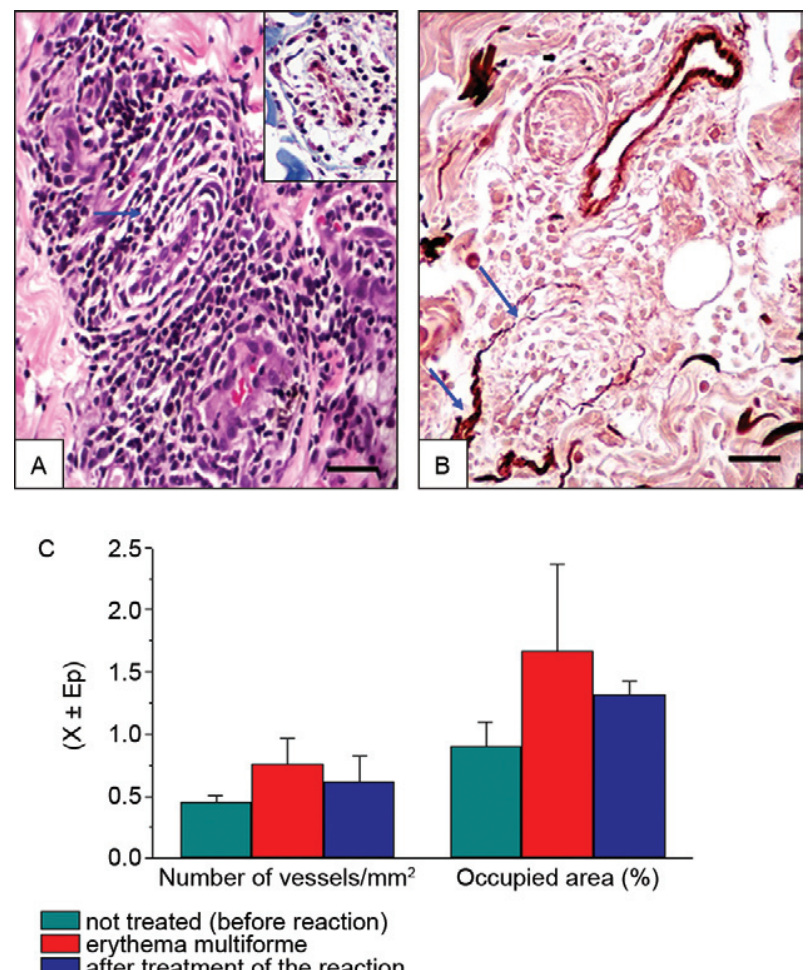

erythema multiforme

after treatment of the reaction

Fig. 2: blood vessels are the main target of erythema multiforme (EM)like lesions pathogenesis. A: typical EM vascular change (arrows) showing dissociation of the wall by oedema and inflammatory cells, mainly lymphocytes, without fibrinoid degeneration (H\&E: $40 \mu \mathrm{m}$ ) (insert: Gomori' strichrome); B: disruption and thickening of elastic layer (arrows) and inflammatory infiltration in the wall of venules (Weigert' sorcein, $65 \mu \mathrm{m}$ ); $\mathrm{C}$ : angiogenesis is significantly increased in EM-like lesions when compared to the biopsy taken for diagnosis purpose (before reaction) and two months after the reactional sample. 
imens that were measured before and during the reactions. The results differed between the skin samples that were taken from the same patients before the treatment and after the reaction subsided. The median value for the number of vessels per square millimetre $\left(\mathrm{mm}^{2}\right)$ varied from 0.444 before treatment to 0.761 during the reaction $(\mathrm{p}<$ 0.05 ). Similarly, the areas occupied by the vessels ranged from $0.878 \%$ before treatment to $1.671 \%$ during the EMlike episode $(\mathrm{p}<0.05)$ (Fig. $2 \mathrm{C})$. The mean number of vessels exhibited statistically significant differences $(\mathrm{p}<$ 0.03 ) and the mean area occupied by the vessels exhibited a borderline significance $(\mathrm{p}<0.06)$. These tests were performed using the data from six patients who were evaluated before and during the reactions.

\section{DISCUSSION}

To date, this study reviews the largest series of leprosy cases presenting EM-like reaction episodes (27 patients) and the data obtained suggest that ENL and EM might represent variants of type II reactions provoked by variations of a common pathogenic mechanism of leprosy reactions. In one patient, one possible causative agent (a cowpox vaccine) was administered a few days prior to the onset of the reaction episode. The literature does not report that MDT drugs are associated with the initiation of EM reactions. However, we cannot exclude the possibility of self-administered drugs as causative agents in the patients in our studies, despite the absence of such drug usage in the patient histories.

Depending on the patient stage (diagnosis, treatment and post-discharge), the frequency of EM-like reactions was similar to that observed for the incidence of ENL in lepromatous patients (Pocaterra et al. 2006).

The LPs presenting with reactional EM-like lesions lacked mucosal and plantar/palmar lesions and the histopathological examination of the lesions revealed a low incidence of apoptotic cells. Both of these features are commonly observed in EM lesions that are unrelated to leprosy (Fritsch \& Maldonado 1999). Our histopathological examination did not reveal regularly occurring bullae, a finding that may be attributed to the fact that we sampled bullous lesions from the border regions, but not from the fully developed central areas. This approach avoided epidermal detachment and shifting during the process.

The findings concerning the vascular changes observed in EM-like lesions are similar to those already described in the hypodermis within the ENL lesions and suggest that dermal microvessels (primarily capillaries and venules) represent relevant targets in the EM-like lesions and in the ENL lesions during the pathogenesis of leprosy.

The clinical and histopathological differences between the ENL and the EM-like reactions suggest that a mediator is somehow activated, which could induce increased vascular permeability within the superficial dermis, thus accounting for the subepidermal oedema and occasional bullae formation in the EM-like lesions.

The immunohistological profile displayed a transient increase in CMI, such as increased CD4/CD8 ratios, increased expression of ICAM1, HLA-DR, TNF and increased numbers of LCs. This pattern has also been previously reported in ENL samples by our group and others (Thangaraj et al. 1988, Sullivan et al. 1991, Sampaio et al. 1993, Miranda et al. 2007). However, no differences in immunological activation between classical ENL and the EM-like episodes could be detected by the markers that were employed in this study.

The increased expression of immunological activation markers found in this investigation are consistent with Modlin et al. (1986), who found an increase in the cell-mediated immune response with increased levels of interleukin (IL)-2 and of IL-2 receptor (Tac) in ENL. Furthermore, recent studies on the immunoregulation of the CMI in ENL patients receiving thalidomide treatment revealed that a complex immunostimulatory action was exerted by the t-helper (Th)17 cells (Martiniuk et al. 2012). This stimulation occurred during the recovery from the reaction symptoms. According to the authors, the effectiveness of thalidomide used in the treatment of ENL lesions was associated with the upregulation of immunostimulatory cytokines (IL-21 or IL-17C) as well as ROR $\gamma \mathrm{T}$ and aryl hydrocarbon receptor nuclear translocator, which are Th17 transcription factors. In contrast to the enhanced immune activity, thalidomide also increased the levels of $\mathrm{FoxP}^{+} / \mathrm{CD}^{+} / \mathrm{CD} 25^{+}$Treg cells, which are a subset of immunoregulatory T-cells. Therefore, the ENL recovery induced by thalidomide resulted from a balance of immunostimulation and immunoregulation, a "yin and yang" role of the Th17 cytokines.

Th17 cells are involved in the crosstalk between neutrophils in psoriasis; speculatively, they might play a role in the neutrophil infiltration that occurs in ENL lesions (Pelletier et al. 2010). $\gamma \delta$ T-cells are reportedly the source of IL-17 in chronic inflammatory autoimmune diseases (Cai et al. 2011).

Transforming growth factor $\beta$ and the inducible NO synthase were reported to be associated with type 1 and type 2 reaction episodes (Lockwood et al. 2011) and were proposed as prognostic tissue indicators of leprosy reactions. Souza et al. (2012) reported a genetic polymorphism of IL-6 that is associated with the susceptibility of LPs to type II reactions. The diversity of mediators involved in the reaction episodes and the minor but critical differences between the distinct types of reactions (e.g., EM-like episodes and ENL) make the immunopathogenesis of type I and type II leprosy reactions a complex issue. Determining the precise contribution of each mediator to the final clinical presentation of the specific reactional episode remains a challenge.

The morphometric analysis of angiogenesis has revealed the presence of increased numbers of vessels in the active EM-like lesions compared to the skin before the reaction episode and after the remission of the lesion. This result is consistent with the frequent observation of prominent vascular involvement in the type II reactions.

Some patients who have persistent EM attacks that are apparently unrelated to leprosy have exhibited positive responses to thalidomide (Cornejo-Mir et al. 2003). Recent findings concerning the pharmacological actions of thalidomide, a drug used to generally treat type II reactions, support its potential use in the treatment of EM. Apart from its immunoregulatory and immunostimula- 
tory role (Martiniuk et al. 2012), thalidomide can act in pre and post-transcriptional manners. It can interfere with angiogenesis and with the transcription factor binding to the $b F G F$ gene promoter and it also diminishes the halflife of TNF RNA, attenuating the effects of this important inflammatory cytokine (Moreira et al. 1993, 1999).

The findings from the 27 cases presented in this study can guide clinicians in making a differential diagnosis of EM lesions, particularly in patients from countries in which leprosy is endemic. The clinical appearance and the histological findings supported the diagnosis of EM in all of the cases, although important characteristics of this syndrome were not found in LPs. This factor is particularly important for those clinicians who do not routinely treat LPs. Pathologists should be familiar with the morphological aspects of this disease and should examine the biopsy specimens and skin smears for evidence of leprosy whenever EM is suspected. The profile of immunological markers and the increased angiogenic pattern observed in the histological sections of the cutaneous lesions suggest that EM-like lesions might represent a variant or a concomitant event that occurs during the type II reactions. In this study, it was impossible to determine the exact association of the EM-like episodes reported with ENL.

Despite the low incidence, the actual prevalence of EM-like lesions within the entire leprosy population of patients is difficult to determine, as public leprosy reference centres have biased the incidence of leprosy complications. Moreover, there is a lack of detailed assessments of the cases that have been diagnosed as EM. In conclusion, the appearance of EM-like lesions might indicate an on-going type II reaction in LPs; moreover, it may be the first clinical manifestation of undiagnosed leprosy.

\section{REFERENCES}

Antunes SL, Mota E, Almeida SMR, Gallo MEN, Nery JAC, Lenzi HL 2000. Distinct patterns of microvasculature in the cutaneous lesions of leprosy. Int J Lepr 68: 143-151.

Bhandarkar SS, Cohen C, Kuruvila M, Rea TH, MacKelfresh JB, Lee DJ, Modlin RL, Arbiser JL 2007. Angiogenesis in cutaneous lesions of leprosy. Arch Dermatol 143: 1527-1529.

Brice SL, Krzemien D, Weston WL, Huff JC 1989. Detection of herpes simplex virus DNA in cutaneous lesions of erythema multiforme. J Invest Dermatol 93: 183-187.

Bryceson A, Pfalzgraff RE 1990. Immunological complications: reactions. In Leprosy. Medicine in the tropics, 3rd ed., Churchill Livingstone, Edinburgh, p. 115-126.

Cai Y, Shen X, Ding C, Qi C, Li K, Li X, Jala VR, Zhang HG, Wang T, Zheng J, Yan J 2011. Pivotal role of dermal IL-17-producing $\gamma \delta$ $\mathrm{T}$ cells in skin inflammation. Immunity 35: 596-610.

Cornejo-Mir JS, del Canto S, Muñoz MA, Rodríguez-Freire L, Serrano A, Hernandez C, Pulpillo A 2003. Thalidomide as elective treatment in persistent erythema multiforme - report of two cases. J Drugs Dermatol 2: 40-44.

Esquenazi D, Moreira AL, Miranda A, Nery JA, Alvarenga FF, Sarno EN, Pereira GM 2008. Clinical, immunological and histological aspects of an uncommon type II reaction in patients with lepromatous leprosy. Clin Exp Dermatol 33: 294-297.
Folkman J, Klagsbrun M 1987. Angiogenic factors. Science 235: 442-444.

Folkman J, Shing T 1992. Angiogenesis. J Biol Chem 267: 1093110934.

Fritsch PO, Maldonado R 1999. Erythema multiforme. In TB Fitzpatrick, AZ Eisen, K Wolff, IM Freedberg, KF Austen (eds.), Fitzpatrick's dermatology in systemic medicine, Vol. 1, MacGrawHill, New York, p. 636.

Ganapati R, Pai VV 2004. Reactions and their management. J Indian Med Assoc 102: 688-690.

Gonzalez-Delgado P, Blanes M, Soriano V, Montoro D, Loeda C, Niveiro E 2006. Erythema multiforme to amoxicillin with concurrent infection by Epstein-Barr virus. Allergol Immunopathol (Madr) 34: 76-78.

Illarramendi X, Carregal E, Nery JA, Sarno EN 2001. Progression of acral bone resorption in multibacillary leprosy. Acta Leprol 12: 29-37.

Laal S, Bhutani LK, Nath I 1985. Natural emergence of antigen-reactive $\mathrm{T}$ cells in lepromatous leprosy patients during erythema nodosum leprosum. Infect Immun 50: 887-892.

Lockwood DN, Suneetha L, Sagili KD, Chaduvula MV, Mohammed I, van Brakel W, Smith WC, Nicholls P, Suneetha S 2011. Cytokine and protein markers of leprosy reactions in skin and nerves: baseline results for the North Indian INFIR cohort. PLoS Negl Trop Dis 5: 1-17.

Martiniuk F, Giovinazzo J, Tan AU, Shahidullah R, Haslett P, Kaplan G, Levis WR 2012. Lessons of leprosy: the emergence of TH17 cytokines during type II reactions (ENL) is teaching us about Tcell plasticity. J Drugs Dermatol 11: 626-630.

Miranda A, Amadeu TP, Schueler G, Alvarenga FB, Duppre N, Ferreira H, Nery JA, Sarno EN 2007. Increased Langerhans cell accumulation after mycobacterial stimuli. Histopathology 51: 649-656.

Modlin RL, Bakke AC, Vaccaro AS, Horwitz DA, Taylor CR, Rea TH 1985. Tissue and blood T-lymphocyte subpopulations in erythema nodosumleprosum. Arch Dermatol 121: 216-219.

Modlin RL, Mehra V, Jordan R, Bloom BR, Rea TH 1986. In situ and in vitro characterization of the cellular immune response in erythema nodosum leprosum. J Immunol 136: 883-886.

Moraes MO, Sarno EN, Almeida AS, Saraiva BCC, Martins RC, Nery JAC, Sampaio EP 1999. Cytokine mRNA expression in leprosy reaction: a possible role for IFN- $\gamma$ and IL-12 in reactions (RR and ENL). Scand J Immunol 50: 541-549.

Moreira AL, Friedlander DR, Kaplan G, Zagzag D 1999. Thalidomide and a thalidomide analogue inhibit endothelial cell proliferation in vitro. J Neurooncol 43: 109-114.

Moreira AL, Sampaio EP, Zmuidzinas A, Smith KA, Kaplan G 1993. Thalidomide exerts its inhibitory action on tumor necrosis alpha by enhancing mRNA degradation. $J$ Exp Med 177: 1675-1680.

MS/SVS - Ministério da Saúde/Secretaria de Vigilância em Saúde 2011. Situação epidemiológica da hanseníase em 2011. Available from: portalsaude.saude.gov.br/portalsaude/arquivos/pdf/2012/ Jan/26/hanseniase_2011_final.pdf.

Nery JAC, Vieira LMM, Matos HJ, Gallo MEN, Sarno EN 1998. Reactional states in multibacillary Hansen disease patients during multidrug therapy. Ver Inst Med Trop S Paulo 40: 363-370.

Pelletier M, Maggi L, Micheletti A, Lazzeri E, Tamassia N, Costantini C, Cosmi L, Lunardi C, Annunziato F, Romagnani S, Cassatella MA 2010. Evidence for a cross-talk between human neutrophils and Th17 cells. Blood 115: 335-343. 
Pocaterra L, Jain S, Reddy R, Muzaffarullah S, Torres O, Suneetha S, Lockwood DN 2006. Clinical course of erythema nodosum leprosum: an 11-year cohort study in Hyderabad, India. Am J Trop Med Hyg 74: 868-879.

Rea TH, Modlin RL 1993. Leprosy. In TB Fitzpatrick, AZ Eisen, K Wolff, IM Freedberg, KF Dusten (eds.), Fitzpatrick's dermatology in systemic medicine, Vol. 1, MacGraw-Hill, New York, p. 2306.

Ridley DS, Jopling WH 1966. Classification of leprosy according to immunity: a five group system. Int J Lepr 34: 255-273.

Sampaio EP, Kaplan G, Miranda A, Nery JAC, Miguel CP, Viana SM, Sarno EM 1993. The influence of thalidomide on the clinical and immunological manifestation of erythema nodosumleprosum. J Infect Dis 168: 408-414.

Sarno EN, Grau GE, Vieira LMM, Nery JA 1991. Serum levels of tumor necrosis factor-alpha and interleukin-1 beta during leprosy reactional states. Clin Exp Immunol 84: 103-108.
Sato N, Nariuchi H, Tsuruoka N, Nishihara T, Beitz JG, Calabresi P, Frackelton Jr AR 1990. Actions of TNF- $\alpha$ and IFN- $\gamma$ on angiogenesis in vitro. J Invest Dermatol 95 (Suppl.): $85 \mathrm{~s}-89 \mathrm{~s}$.

Souza AL, Fava VM, Sampaio LH, Martelli CM, Costa MB, Mira MT, Stefani MM 2012. Genetic and immunological evidence implicates interleukin 6 as a susceptibility gene for leprosy type 2 reaction. J Infect Dis 205: 1417-1424.

Sullivan L, Sano S, Pirmez C, Salgame P, Mueller C, Hofman F, Uyemura K, Rea TH, Bloom BR, Modlin RL 1991. Expression of adhesion molecules in leprosy lesions. Infect Immun 59: 4154-4160.

Thangaraj H, Laal S, Thangaraj I, Nath I 1988. Epidermal changes in reactional leprosy: keratinocytes Ia expression as an indicator of cell-mediated immune responses. Int J Lepr 56: 401-417.

Wemambu SNC, Turk JL, Waters MFR 1966. Erythema nodosum leprosum: a clinical manifestation of the Arthus phenomenon. Lancet 2: 933-936. 